\title{
Novas fronteiras de pesquisa na sociologia do trabalho
}

\author{
José Ricardo Ramalho*
}

$U^{2}$ m conjunto de novos temas e a exigência de novas interlocuções tem obrigado a sociologia do trabalho a repensar sua tradição teórica e disciplinar. O estudo das transformações resultantes do processo de globalização, em especial aquelas voltadas para a organização produtiva e para a flexibilização das relações de trabalho, colocou em questão a capacidade explicativa do seu corpo conceitual ao mesmo tempo em que abriu janelas de diálogo com outras perspectivas analíticas anteriormente consideradas distantes ou não pertinentes a esta área do conhecimento. A proposta deste texto é identificar e problematizar as novas fronteiras da interpretação sociológica, tomando como exemplo a pesquisa que venho realizando sobre relações de trabalho e sindicato em distritos industriais brasileiros ligados ao setor automotivo ${ }^{1}$.

Pesquisar o trabalho industrial em contextos políticos e econômicos reestruturados pelas exigências do mercado mundial transformou-se em um desafio, porque a sociologia do trabalho consolidou-se teoricamente na investigação do universo produ-

Professor e pesquisador do Programa de Pós-Graduação em Sociologia e Antropologia (PPGSA) da UFRJ. Publicou recentemente as seguintes coletâneas Trabalho e Sindicato em Antigos e Novos Territórios Produtivos, com Iram Jácome Rodrigues (São Paulo: Annablume, 2007) e Trabalho e Desenvolvimento Regional Efeitos Sociais da indústria automobilística no Rio de Janeiro, (Rio de Janeiro: Mauad X, 2006). Endereço eletrônico: jramalho@ifcs.ufrj.br.

1 Este texto foi elaborado a partir de resultados parciais de projetos de pesquisa apoiados pelo Conselho Nacional de Desenvolvimento Científico e Tecnológico CNPq e pela Fundação de Amparo à Pesquisa do Estado do Rio de Janeiro - FAPERJ, através do Programa Cientistas do Nosso Estado e do Projeto Pensa Rio. 


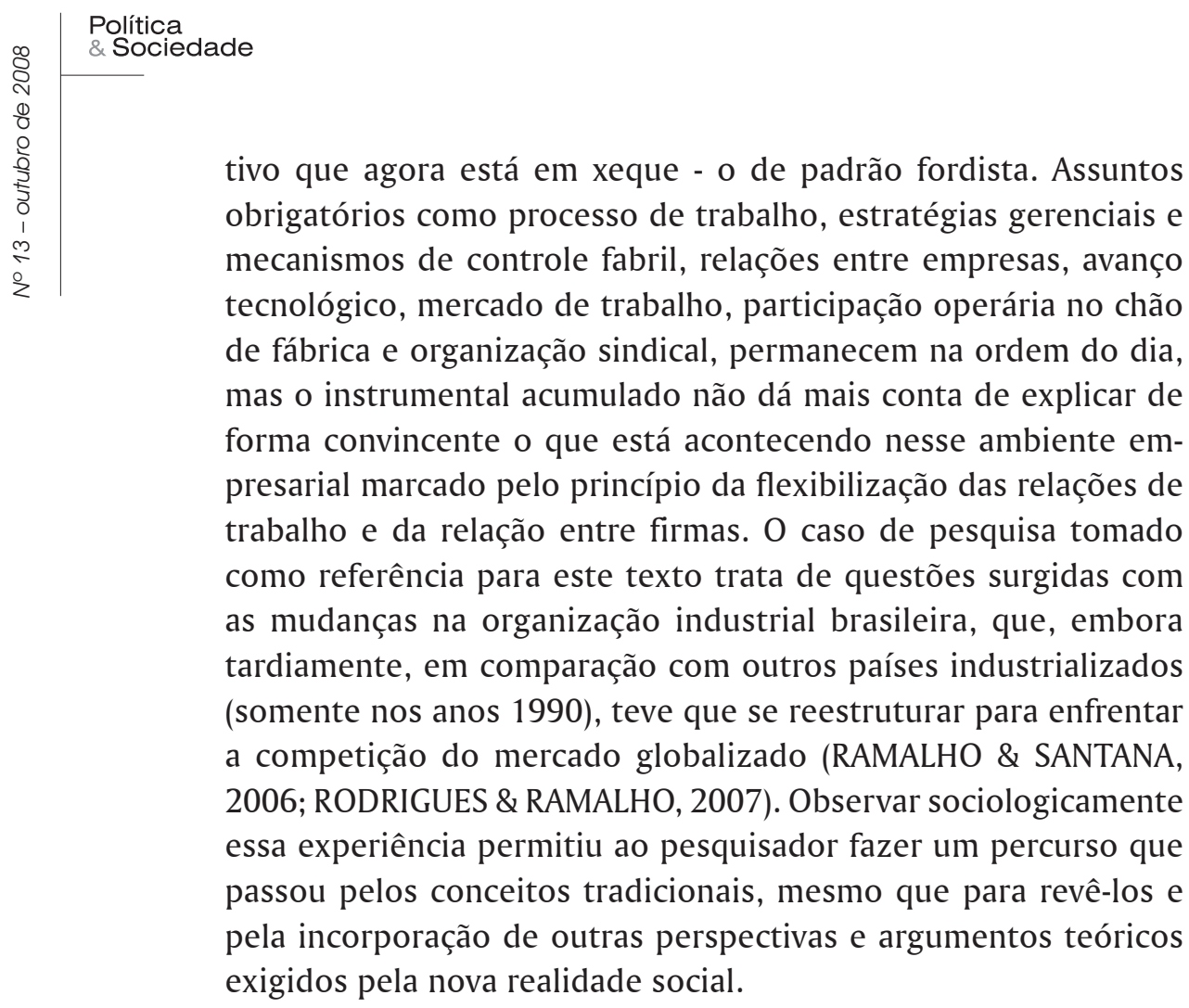

\section{O debate sobre reestruturação produtiva}

O estudo da implantação de novas estratégias produtivas no setor industrial automobilístico brasileiro e mundial tem oferecido uma oportunidade bastante proveitosa para alargar o debate teórico em torno do que se denominou, de modo mais genérico, como "reestruturação produtiva", mas que nos seus detalhes tem a ver com a ampliação das cadeias produtivas (agora com características globais), com a constituição da "empresa em rede" (com alterações no modelo de fábrica fordista e no relacionamento interfirmas), com a horizontalização da produção e o crescimento da subcontratação de empresas e com a re-divisão de trabalho entre elas (que no Brasil recebeu o nome de "terceirização"). Nesse contexto, por exemplo, está o caso emblemático do "consórcio modular" da empresa Volkswagen na cidade de Resende (RJ), que resumiu em uma fábrica a experiência mais ousada de "produção enxuta" e "terceirização", transformando-se em um paradigma de novo modelo produtivo. 
As alterações no processo de trabalho resultaram em novas estratégias gerenciais, redefinindo mecanismos de controle e dominação sobre o operariado. Isto também vem exigindo do pesquisador especial atenção para com outras formas de resistência articuladas pelos trabalhadores que, neste novo contexto, parecem vulneráveis e inseguros com relação à estabilidade dos seus postos de trabalho e vivendo uma situação da qual o acúmulo político e reivindicativo, construído à duras penas, ao longo do período fordista, tinha perdido o efeito. Percebem-se, também, mudanças na ação coletiva dos trabalhadores, principalmente em instituições como sindicato e órgãos de representação fabril como as comissões de fábrica, que buscam estabelecer novas práticas políticas como forma de enfrentar uma conjuntura bastante desfavorável.

Hoje, a composição do operariado das fábricas de veículos tem características bem diferentes dos primórdios desse setor industrial no Brasil. Uma maioria de jovens escolarizados trabalha intensamente (embora os salários tenham decrescido na média nacional), sente-se impelida a estudar mais, mas não consegue sentir-se segura no emprego. O poder de barganha empresarial, no que diz respeito aos empregados, é maior no modelo de produção enxuta, e, embora os trabalhadores tenham empregos formais, acabam fragilizados por um mercado de trabalho marcado pela informalização das atividades econômicas, e pela precarização do trabalho.

$\mathrm{O}$ termo que tem sido mais utilizado para resumir todos esses novos procedimentos é "flexibilização". Abordar a questão da flexibilização tornou-se central para os estudos dedicados à problemática do desenvolvimento industrial. Seus diferentes usos permitem identificar os atores sociais que se aproveitam de sua novidade para criar novos padrões de relações de trabalho. A utilização política do termo e de suas definições transformou-se, em si, em um interessante objeto de estudo (RAMALHO, 2000).

A reestruturação da cadeia produtiva automotiva criou condições para uma maior mobilidade das empresas, o que imediatamente proporcionou um deslocamento geográfico de fábricas nunca antes imaginado. No caso brasileiro, o estabelecimento por parte do governo federal de um "novo regime automotivo", em meados dos anos 1990, com a concessão de substantivos incentivos fiscais, foi a senha 
para que as montadoras de veículos instaurassem uma segunda fase de grandes investimentos no país. Diferentemente da primeira fase nos anos 1950, quando as empresas concentraram-se no complexo distrito industrial do $\mathrm{ABC}$ paulista, desta vez a expansão industrial espalhou-se por outras regiões e municípios, carregando consigo muitas expectativas de empregos e desenvolvimento econômico.

A investigação de duas regiões que compõem o setor automotivo, uma sedimentada e madura (o ABC paulista) e outra recém integrada (o Sul fluminense), levou o pesquisador a integrar no debate sobre as questões do trabalho outras questões relacionadas ao desenvolvimento econômico, ao território/região e ao modo como as localidades reinventam-se e defendem-se a partir das exigências colocadas pelas novas atividades econômicas, pelas crises oriundas do processo de reestruturação, pelas mudanças no perfil do mercado de trabalho; com a formação de redes sócio-políticas instauradas a partir das necessidades colocadas pelas demandas empresariais e com a criação de instâncias institucionais para reunir os principais atores sociais e discutir os desdobramentos, ora da crise, ora do sucesso do novo contexto econômico. O que vem a seguir é um breve relato de algumas das questões colocadas no contexto social da pesquisa e que trazem desafios de interpretação...

\section{Novos padrões de organização da produção}

A indústria automotiva tem laços fortes com o processo de industrialização brasileiro e sua história de desenvolvimento econômico. A partir dos anos 1950, principalmente no ABC paulista, uma fase de investimento externo em novas fábricas proporcionou a constituição de um aglomerado de empresas com grande dinamismo e influência econômica e social. No que hoje se poderia chamar de o mais complexo distrito industrial do país, essa região periférica à cidade de São Paulo transformou em um pólo de atração de trabalhadores, na maioria migrantes, em um centro urbano com grande dinamismo político e em uma economia que, pelo lado do setor metalúrgico, passou a representar uma fatia significativa da produção industrial. A história regional prévia, com presença de outros setores industriais mais tradicionais e de capital nacional, 
agregou-se à história da introdução do capital internacional e de seus desdobramentos em termos de transformações na economia e na formação de uma classe operária atuante politicamente. Esse conjunto expressivo de empresas permitiu também o crescimento e o fortalecimento dos sindicatos operários desse setor.

De maneira associada, e como reflexo do que se passa em nível internacional, o setor automotivo do país entra em uma fase de reorganização a partir dos anos 1990, como consequiência da crise de produtividade no âmbito internacional e de um período de recessão econômica no mercado interno, associado ao abandono da política de substituição de importações (ABREU et alii, 2000). O país tornouse um importante alvo dos investimentos diretos de montadoras, graças aos incentivos fiscais de um "novo regime automotivo", que se traduziram na construção de novas fábricas e na reestruturação das antigas. Nesse contexto, houve também a implementação de uma nova estratégia de localização industrial, com a busca de localidades afastadas das áreas industriais mais tradicionais.

Esse é o caso da instalação das fábricas da Volkswagen Ônibus e Caminhões (1996) e da PSA Peugeot Citroën (2001), nos municípios de Resende e Porto Real, no Estado do Rio de Janeiro. Os efeitos dos investimentos logo se fizeram sentir nas economias locais, com o crescimento dos recursos públicos, da instalação de outras empresas e do setor de construção civil, dos postos de trabalho e das atividades de serviços.

No debate teórico sobre "reestruturação produtiva", o estudo das mudanças ocorridas nas empresas, quando referido às duas regiões, revela características distintas de um mesmo processo e refina as possibilidades de explicação sobre seus desdobramentos na vida social. No caso do $\mathrm{ABC}$, a reestruturação levou a um enxugamento das fábricas, a uma redução da força de trabalho e a uma crise regional. Os mecanismos utilizados foram no sentido de readaptar as velhas estruturas fabris às novas exigências da organização produtiva, a despeito dos custos sociais que causariam em termos de desemprego e desalento. Essa situação implicou em um intricado processo de negociação política que envolveu não só os trabalhadores através dos sindicatos, mas também outros atores sociais locais e regionais afetados pelas medidas adotadas pelas empresas. 
No interior da fábrica, a introdução de mecanismos de controle com exigência de qualidade e trabalho de time, a intensificação das tarefas no cotidiano fabril e a flexibilização das relações de trabalho, aliados às ameaças reais de desemprego e/ou deslocamento da fábrica para outras regiões, dificultaram a atuação dos sindicatos e colocaram em xeque práticas anteriores de ação política. As instituições de representação operária - sindicato e comissões de fábrica - tiveram que se dividir entre negociações pela manutenção de empregos e das atividades econômicas na região com as atividades habituais de negociar salários e exigir melhores condições de trabalho. Em resumo, as questões colocadas pela reestruturação neste contexto introduzem no debate e na análise o componente da insegurança o emprego que se instala no meio operário, dentro e fora da fábrica, e que repercute, com a redução dos postos de trabalho na indústria, nas regiões onde vivem esses trabalhadores, ora confirmando uma fase de decadência econômica, ora promovendo novas formas de ação coletiva que apontam para a criação de diferentes instâncias de cooperação e conflito na esfera pública das localidades.

No caso do Sul fluminense, as localidades já foram selecionadas com o objetivo explícito de abrigar experiências produtivas pós-reestruturação, saltando, portanto, a fase dos ajustes sociais que atingiram em cheio o $\mathrm{ABC}$. O preço da força de trabalho (mais baixo) tinha sido pré-condição para a instalação das novas fábricas, além das generosas renúncias de impostos. O recrutamento dos trabalhadores partiu de um patamar de exigência escolar (segundo grau completo) que o distinguia de outras épocas, e a força do sindicato não alcançava o grau de militância identificado na região paulista. $O$ fato da fábrica da VW de Resende ter sido palco de uma experiência pioneira de organização do sistema produtivo - o "consórcio modular” - eleva a curiosidade sociológica sobre seus efeitos, não só sobre as outras empresas que participam como consorciadas, como também sobre os trabalhadores e a ação sindical. Nesse exemplo, a fábrica pode ser considerada um lócus privilegiado para se observar um modelo que já foi rapidamente copiado por outras empresas e transformou-se em um padrão mundial (no Brasil mesmo, a modularização está presente nas fábricas da Ford em Camaçari, na Bahia, e da General Motors, em Gravataí, no Rio Grande do Sul). 
Para os estudos sobre padrões de desenvolvimento industrial, o "consórcio modular" da VW revela a sua radicalidade ao propor uma divisão inusitada de tarefas entre empresas que participam do processo produtivo, todas sob o mesmo teto, de tal forma que abdica concretamente da tarefa da montagem do veículo, mas continua controlando os nós essenciais da linha de montagem, da engenharia dos produtos, do design e da venda, conforme Abreu, Beynon e Ramalho (2006). Todo o debate teórico sobre as relações entre firmas nessa cadeia produtiva precisa ser revisto à luz dessa experiência, assim como as questões relativas ao processo de terceirização, que nesse exemplo funcionam em bases diferentes do modo tradicional. Em resumo, o impacto da empresa enxuta, já reestruturada, em novas localidades, ressalta aspectos e características diferentes daquelas observadas no ABC. Não é uma crise de decadência econômica que se coloca, ao contrário, a perspectiva regional é de crescimento e novas estratégias de desenvolvimento. Não é o desemprego, mas o crescimento do emprego formal. Não é a diferença geracional no meio operário, mas a formação de uma classe operária jovem e com pouca experiência sindical. Como no $\mathrm{ABC}$, revelam-se algumas iniciativas de ação coletiva, não em busca de estratégias para enfrentar a crise, mas com o objetivo de articular fórmulas que potencializem positivamente o impacto econômico trazido pela vinda das empresas para a região.

\section{A questão sindical}

O deslocamento dos investimentos das montadoras para outras regiões brasileiras, evitando o $\mathrm{ABC}$ paulista, teve entre os seus principais motivos a busca de localidades com mão de obra mais barata e presença sindical pouco efetiva. A crise pela qual passa o sindicalismo em geral, como consequiência do processo de reestruturação, também se aplica ao setor metalúrgico e de produção de veículos. Qualquer discussão teórica sobre processos de ação coletiva associados à classe trabalhadora fabril e sobre sua principal instituição de representação no mundo capitalista industrial, o sindicato, precisa levar em conta que antigas práticas políticas mostraram-se defasadas diante das novas estratégias gerenciais e diante do modo 
como se reconstituiu o mercado de trabalho; além de que novas práticas coletivas enfrentam as dificuldades relativas a uma desfiguração gradativa do trabalho como fator fundamental para a formação de uma identidade e de um sentimento de pertencimento social.

No caso do $\mathrm{ABC}$, a reestruturação das empresas colocou a instituição sindical em dificuldades. No tempo da ditadura militar, o sindicato dos metalúrgicos de São Bernardo (hoje, sindicato dos metalúrgicos do $\mathrm{ABC}$ ) protagonizou um enfrentamento com o regime que ultrapassou os limites regionais e transformou-se em exemplo de resistência e de luta pelas liberdades democráticas. Esse poder de reivindicação e de pressão política permaneceu mesmo com o fim da ditadura. No contexto da reestruturação, esse capital político e simbólico acumulado garantiram algum poder de barganha, mas o sindicato teve que mudar sua estratégia de enfrentamento, inaugurando uma nova agenda de negociação, diante da redução dos postos de trabalho e do aumento do desemprego. A globalização da cadeia produtiva levou dirigentes sindicais a reformular suas estratégias, apelando para uma organização integrada de trabalhadores de toda a rede de empresas do setor, e para reivindicações de caráter internacional que sensibilizassem o mercado consumidor dos seus produtos. Da mesma forma, reforçou a cobrança pela responsabilidade social das empresas e do compromisso que assumiram com os destinos das localidades onde estão inseridas.

No Sul fluminense, a vinda das montadoras alterou a composição do mercado de trabalho ao recrutar um significativo grupo de trabalhadores formais. Criou-se, de fato, uma nova classe operária na região, ligada agora à indústria automotiva (a tradição do município mais industrializado da região, Volta Redonda, sempre foi a siderurgia), e com uma identidade de classe construída a partir de uma cultura empresarial globalizada e, por isso, socializada para um intercâmbio maior com grupos operários de outras fábricas em outras regiões e, até mesmo, de outros países. Foi nesse contexto que o sindicato dos metalúrgicos de Volta Redonda, responsável pela representação dos trabalhadores das montadoras, com longa tradição de representação no setor siderúrgico (principalmente da Companhia Siderúrgica Nacional - CSN), viu-se diante da necessidade de pensar novas práticas, tendo em vista esse universo de 
operários mais jovens e escolarizados, sem trajetória prévia em empregos industriais e com demandas diferentes das tipicamente defendidas pelo sindicato; além das diferentes formas de organização do processo produtivo enxuto e flexibilizado da indústria automotiva (RODRIGUES \& RAMALHO, 2007a).

Embora as montadoras, em suas decisões de investimento, tenham preferido regiões de tipo greenfield (na verdade, houve a criação de um universo greenfield dentro de uma região com tradição industrial siderúrgica), por razões ligadas à deficiência e às dificuldades de organização e mobilização sindical, essa estratégia teve seus efeitos relativizados pela capacidade do sindicato de rapidamente organizar e mobilizar operários, promovendo reivindicações que, no caso da VW, criaram espaço político para o funcionamento de uma comissão de fábrica. A instalação das fábricas em Resende e Porto Real obrigou a uma transformação do sindicalismo regional. A atividade e a participação sindical metalúrgica cresceram em quantidade e qualidade com a indústria automotiva (RAMALHO, 2005). Em resumo, esse segundo exemplo amplia o debate acerca da questão sindical e operária em experiências produtivas de novo padrão flexível e ajuda a entender a constituição de novos mecanismos de ação coletiva dentro e fora da fábrica. A organização de uma resistência no chão de fábrica que se comunica e solidariza-se com outras organizações no Brasil e no exterior, o uso efetivo da rede interna das próprias empresas para buscar tratamento mais igualitário e derrubar as "vantagens comparativas" que movem fábricas inteiras para vários lugares do planeta, a confirmação do sindicato como real interlocutor do empresariado, todos esses elementos alargaram a compreensão marcada pelo desempenho adaptado à estrutura produtiva fordista.

\section{Localidades, regiões, territórios produtivos}

Se a presença de empresas da indústria automotiva sempre despertou grandes expectativas nas localidades e regiões onde se instalavam, pela extensão da cadeia produtiva e pelo aumento do número de trabalhadores recrutados e das atividades econômicas, os novos investimentos e as novas estratégias da indústria automotiva 
globalizada e flexibilizada trouxeram outros tipos de relacionamento e outras implicações econômicas e políticas entre perspectivas globais e locais, entre as empresas multinacionais e os territórios produtivos. A pesquisa de duas regiões atingidas distintamente por essas estratégias introduz temas pouco comuns ao debate da sociologia do trabalho, mas que se tornaram essenciais para a compreensão da lógica das empresas, da transformação do mercado de trabalho e da ação coletiva dos trabalhadores. O desemprego e as novas exigências com relação à mão de obra, por exemplo, tem afetado severamente as localidades e forçado a busca de alternativas que envolvem um conjunto maior de atores sociais não necessariamente ligados à produção industrial, mas envolvidos nos destinos políticos e econômicos regionais. Por outro lado, nas regiões selecionadas para os investimentos recentes, as preocupações encaminham-se no sentido de condições de usufruir e implementar estratégias regionais que atraiam novos investimentos e agreguem atividades complementares àquelas trazidas pela indústria.

A reestruturação de empresas no $A B C$ empurrou a região para uma crise econômica que exigiu grande mobilização das lideranças de diferentes áreas - dos políticos aos trabalhadores e empresários, passando por instituições da sociedade civil, através de instâncias criadas especialmente para debater os destinos regionais. Essas iniciativas, com características de inovação institucional, configuram um tipo diferente de reação às mudanças implementadas pelas montadoras, e tiveram nos sindicatos, em algumas empresas e nas administrações municipais grandes estimuladores (RODRIGUES \& RAMALHO, 2007).

A organização e discussão de alternativas à crise econômica regional imposta pela lógica das empresas multinacionais de veículos reuniram atores variados em iniciativas que trouxeram para o espaço público das localidades um debate em geral restrito à lógica de funcionamento das empresas e definidos fora da região. A participação dos sindicatos na câmara setorial automotiva, na primeira metade dos anos 1990, demonstrou a importância de articular-se para além das questões fabris (condições de trabalho, salários etc.), negociando alternativas para manter a produção em patamares compatíveis com a preservação de empregos (ARBIX, 
1996). Diante de uma fase mais aguda de reestruturação, nos últimos anos da década de 1990, forças institucionais dispersas como o consórcio intermunicipal (que reunia as sete prefeituras da região do $\mathrm{ABC}$ ), o fórum da cidadania (que reunia os principais movimentos sociais) e o empresariado local (pequenos e médios), preocupados com as consequiências do deslocamento de investimentos estrangeiros para outras partes do Brasil, uniram-se para a criação da Câmara Regional do Grande ABC.

Nesse caso, a questão sociológica que se coloca envolve novas formas coletivas de organização. Segundo um dos atores principais desse processo, o formulador de políticas e ex-prefeito de Santo André (SP), Celso Daniel (2001, p.464), o desafio institucional estava em como

"diferentes agentes, sem abrir mão de seus interesses, ou, mais propriamente, partindo deles e de suas visões especificas sobre a realidade, sensibilizados por uma situação que podia afetá-los negativamente, seriam capazes de discutir, elaborar e colocar em prática ações coletivas baseadas na cooperação mútua”.

Na sua definição, sem ser formalmente uma instituição, essa experiência no $\mathrm{ABC}$ apontaria para a constituição de "uma esfera pública democrática que envolve setores do Estado e da sociedade, com o intuito de produzir e implementar uma estratégia regional de desenvolvimento econômico" (2001, pg.467) . Em resumo, a partir de uma temática típica da sociologia industrial e do trabalho, ou seja, a reestruturação da indústria e das relações de trabalho em um contexto globalizado, uma nova pauta impôs-se, trazendo questões relativas a outras formas de ação coletiva ligadas aos territórios produtivos, a outras formas de articulação institucional e política da qual os assuntos relativos ao trabalho, ao sindicato e ao desenvolvimento econômico baseado no setor industrial automotivo são parte integrante e essencial.

No caso do Sul Fluminense, a reestruturação produtiva se manifestou através de novos investimentos e de grande expectativa para as populações das localidades envolvidas. Diferentemente do $\mathrm{ABC}$, a região identifica um crescimento expressivo das atividades 
econômicas causadas pela cadeia produtiva automotiva, incluindo o recrutamento de um número relativamente grande de operários. Embora vizinhos de municípios com tradição industrial siderúrgica (principalmente Volta Redonda com a CSN), Resende e Porto Real se engajaram em um movimento político com vistas a potencializar os novos investimentos e passaram a estimular a constituição do que foi chamado um pólo de desenvolvimento com "vocação para a indústria metal-mecânica”. A história industrial de Resende (incluindo Porto Real, distrito emancipado em meados dos anos 1990), desde os anos 1950, divide-se em diversos ciclos econômicos e sempre esteve associada a grandes firmas, mas não é uma história que chame a atenção pela colaboração entre empresas ou por uma forte ligação com a localidade. No caso da indústria automobilística, embora a tendência inicial tenha sido pela manutenção dessa prática, a dinâmica criada pela instalação das empresas e a expectativa estabelecida pela possibilidade de um novo ciclo de crescimento econômico nos municípios, na região e no Estado parece indicar uma dinâmica diferente das outras épocas. (RAMALHO, 2005).

A questão sociológica que se coloca tem a ver com a possibilidade de empresas integrantes de cadeias produtivas globais, ao instalarem-se em novas localidades e regiões, gerarem dinâmicas criadoras de situações voltadas para o desenvolvimento econômico regional, formando, mesmo que não intencionalmente, novos padrões de participação, atribuindo relevância à ação de redes sociopolíticas presentes nas localidades onde ocorrem as atividades industriais. A unidade básica de análise seria os atores econômicos locais e as redes sociopolíticas formadas por eles, os quais conformariam um padrão particular de desenvolvimento - entre as quais estão empresas e sindicatos. Locke (1995, p.12), por exemplo, descrevendo a experiência italiana, considera que

"essas redes criam misturas de recursos e constrangimentos que moldam as escolhas estratégicas para os atores locais. [...] Não apenas estruturam o fluxo de informações e relações entre as entidades econômicas locais, como também oferecem aos atores locais diferentes ligações ou canais de representação nos grupos nacionais de interesse e criadores de políticas." 
Em resumo, a experiência industrial do Sul fluminense traz para o debate das questões do trabalho, sindicato e indústria uma discussão mais geral sobre experiências de política industrial e desenvolvimento local nas quais a presença de grandes empresas globalizadas em contextos locais pode resultar em uma mobilização positiva da sociedade e na constituição de mecanismos de negociação sobre a utilização dos benefícios gerados pelas atividades industriais. A cooperação entre (pequenas) empresas tem sido a principal ênfase do debate atual sobre estratégias de desenvolvimento industrial em contextos locais, tomando-se quase sempre como exemplo a experiência dos distritos industriais italianos - paradigmas do modelo da especialização flexível (PIORE \& SABEL, 1984). Desconsiderar a presença de grandes empresas em aglomerados industriais e o seu relacionamento com outras empresas e outras instituições estabelecidas no mesmo território, no entanto, tem sido um problema para a análise de várias outras experiências industriais do mundo globalizado. $O$ exemplo em pauta ressalta a complexidade desse novo contexto socioeconômico, que, independente da vontade das grandes empresas, tem tido o efeito de, por um lado, induzir a formulação de novas práticas com vistas a garantir a sustentabilidade econômica (articulação de pequenas e médias empresas com as grandes, preocupação com o meio ambiente, criação de novos fóruns de discussão sobre as necessidades da região e sugestão de alternativas tanto para empresas como para governos municipais) e, por outro lado, tornar pública a discussão sobre as consequiências desse novo perfil produtivo para as relações de trabalho, o mercado de trabalho, as políticas públicas municipais de educação, saúde e segurança e para a sociedade civil organizada, principalmente as organizações de trabalhadores e os movimentos sociais.

\section{Conclusão}

Os dados referentes à investigação desenvolvida nessas duas regiões industriais brasileiras, marcadas pela presença de empresas de uma cadeia produtiva industrial de grande porte e globalizada, confirmam a proposta inicial desse texto, ou seja, a constatação de que os conceitos e explicações tradicionais da sociologia do trabalho 
(em especial voltados para a análise de economias em desenvolvimento como é o caso brasileiro) não são mais satisfatórios para captar uma realidade social transformada por estratégias empresariais e produtivas que alteraram os conceitos de empresa, trabalho fabril e organização sindical. Nesse novo contexto, não só conceitos precisam ser rediscutidos como outros passaram a ser necessários para compor um quadro explicativo mais elucidador do que ocorre na sociedade capitalista atual e no seu setor industrial.

Para finalizar, enumero um conjunto de questões que podem servir de pauta para novas pesquisas e novas discussões sobre a temática do trabalho em experiências de reestruturação industrial ou já como resultado delas:

1) A questão do trabalho e da flexibilidade. Não resta dúvida de que o emprego direto na indústria reduziu-se em termos numéricos nos últimos anos, mas isso não quer dizer que tenha deixado de ser uma referência importante para os que buscam ou estão no mercado de trabalho. O enxugamento das fábricas fez aumentar o número de serviços associados à indústria, alterando o perfil dos trabalhadores envolvidos em todo o processo de manufatura. Nesse aspecto, o que se coloca é a necessidade de discutir as novas dimensões e exigências do emprego neste setor da economia a partir da flexibilização e das novas tecnologias introduzidas na organização da produção. Novas estratégias gerenciais que pressupõem um maior envolvimento e responsabilização dos trabalhadores através da organização em células de produção e trabalho de time, uma redução no nível hierárquico dentro das fábricas, um operário escolarizado e que seja capaz de exercer múltiplas funções, uma intensificação do trabalho; todos esses aspectos revelam os detalhes dos novos mecanismos de controle gerencial e tornam-se alvos inevitáveis de investigação, ainda mais por ser possível, nesse caso, obter diferentes visões dessa realidade a partir das diferentes posições de classe.

2) A questão operária. Exigências das novas estruturas produtivas colocaram sob pressão os operários assim como suas práticas de resistência construídas nos embates cotidianos do chão de fábrica. Observa-se o aumento da margem de independência dos trabalhadores no que se refere à organização do trabalho, como 
resultado do desenvolvimento de novas tecnologias, dos investimentos em treinamento, das gestões mais participativas etc., mas por outro lado, há um agravamento da subordinação, principalmente nos novos tipos de contrato temporários, aumentando o poder de influência da empresa sobre o comportamento operário. Aos argumentos sobre as vantagens de uma maior autonomia contrapõese a estratégia de redefinição da articulação entre o coletivo e o individual, assim como por trás da redefinição de coletivo, de autonomia, estaria ocorrendo uma reapropriação da autonomia dos assalariados por parte das gerências (LINHARDT, 1996, p.64-66). Nas empresas, os dirigentes estariam submetidos a uma grande pressão dos mercados financeiros mundiais, que repercutiria sobre os assalariados por intermédio dos novos modos de gestão de pessoal, com a descentralização da organização produtiva e a concessão de grande autonomia às equipes de trabalho. As equipes autônomas estariam impondo aos assalariados uma mobilidade interna extrema, até mesmo com emprego precário, limitando as possibilidades de emergência de coletivos de trabalho estáveis. A cooperação estaria, portanto, sendo imposta "diretamente pela acentuação das restrições sistêmicas - vinda dos mercados financeiros e de um mercado de trabalho com alto índice de desemprego" (COUTROT, 1998, p.218-220). A autonomia acordada com as equipes seria controlada "pelo jogo dessas restrições e pela presença das exigências da clientela no coração da produção" (APPAY, 1993, p.20-21; APPAY, 1997, p.525-526).

3) A questão social. Embora mais comum nas sociedades que implantaram o estado de bem estar social, mas já presente em contextos de países emergentes como o Brasil, o debate sobre o trabalho pode também ultrapassar os muros da fábrica e ser pensado em termos de sua ligação com a "questão social", colocando-o em lugar de destaque sobre a precariedade, a pobreza e a exclusão. O trabalho precisaria ser pensado "não enquanto relação técnica de produção, mas como um suporte privilegiado de inscrição na estrutura social" (CASTEL, 1998, p.34). Associar trabalho estável e inserção relacional sólida vai caracterizar uma área de integração, enquanto a ausência de participação em qualquer atividade produtiva e o isolamento relacional terá como consequiência os 
efeitos negativos da exclusão. A nova questão social parece ser o questionamento dessa função integradora do trabalho na sociedade, através do desmonte do sistema de proteções e garantias vinculado ao emprego e da desestabilização da ordem do trabalho, que repercute como uma espécie de choque em diferentes setores da vida social. "A problemática da coesão social não é a do mercado, a solidariedade não se constrói em termos de competitividade e de rentabilidade" (CASTEL, 1997, p.165-166).

4) A questão sindical. As mudanças na produção e suas consequiências para os trabalhadores em termos de insegurança no trabalho, precariedade de contratos e desemprego afetou de modo definitivo as práticas sindicais articuladas no período fordista. Está em discussão o modo como a instituição sindical vai reinventar-se à luz da nova conjuntura. Os exemplos de pesquisa referidos no início do texto demonstram que gradativamente a pauta sindical aproxima-se da percepção de que não se pode atuar apenas sobre certos aspectos da realidade dos trabalhadores, mas que se deve considerar a vida do operário em sua totalidade. Por isso, existe uma preocupação com os destinos e a gestão das cidades e da região, com o meio-ambiente, a saúde, a educação, etc. Através de duas pontas distintas na experiência do setor automotivo, os casos estudados demonstram que trabalhadores e sindicatos têm se posicionado de modo a ampliar o seu escopo de atuação assumindo novas responsabilidades e repensando seu modo de intervenção. Isto inclui, além de uma perspectiva diferente de organização e mobilização, a participação em fóruns de debates e a apresentação de propostas sobre temas, como o papel das empresas na sociedade, os problemas da educação, os investimentos econômicos, as questões regionais, associadas à sua preocupação central com a temática do trabalho (RODRIGUES \& RAMALHO, 2007).

5) A questão dos territórios produtivos. A constituição de distritos industriais diferenciados conforme o estágio do processo de reestruturação apresentados nos exemplos mencionados, traz à tona uma temática pouco acionada pela sociologia do trabalho, mas que ganha força diante das novas experiências institucionais estimuladas pela incorporação das localidades e de suas vantagens comparativas com as estratégias das empresas que seguem uma 
lógica internacional (no caso, a indústria automotiva). Esse debate traz também as questões relativas ao papel das pequenas e médias empresas nesse contexto de mercado globalizado. $\mathrm{O}$ caso dos distritos industriais da Terceira Itália reforçou esse aspecto. Nas palavras de Cocco et alii (1999, p.23),

nos distritos industriais estreitam-se de modo radical as relações existentes entre a produção e o território. Apesar da presença maciça de pequenas e médias empresas, a importância da grande organização produtiva - cujo modelo clássico poder ser representado pela grande fábrica fordista verticalmente integrada - permanece. No entanto, a grande unidade fabril deixa de ser a referência da organização produtiva e o território das cidades passa a ocupar tal posição. A analogia entre grande unidade fabril e o território pode ser explicitada de outra forma: não se trata de uma grande fábrica verticalmente integrada, mas de um território integrado, ou integrador, dos diferentes aspectos da produção.

Outro aspecto tem a ver com a importância adquirida pelas cidades. Segundo esses autores,

a transferência do "lugar" da produção para os territórios das cidades extrapola a localização estritamente privada característica do regime de acumulação fordista. Afinal,o espaço da produção, ao deixar a fábrica e passar a se referenciar na cidade (no território), ganha uma conotação pública inexistente anteriormente p.24).

6) A questão do desenvolvimento. Os efeitos econômicos das mudanças das empresas que são essenciais para a existência das localidades e regiões ocorrem de modo diferenciado conforme colocado nos exemplos de pesquisa, no entanto, em ambos os casos, cresceu o debate sobre estratégias de desenvolvimento econômico e social, ora para debelar a crise e decadência, ora para discutir como aproveitar e tornar mais duradouras as novas atividades econômicas. De acordo com Pires (2004, p.3),

o campo do desenvolvimento local ultrapassa a sua valorização dos mercados de bens materiais de consumo, agora envolvendo os serviços, as tradições e os saberes locais, transformados em recursos que dão suporte a várias atividades econômicas, se constituindo em 
elemento estratégico das ações dos atores sociais locais. Isso permite a construção de uma identidade ou imagem do território, através do envolvimento dos atores locais e da diferenciação do local, um fator crucial na concorrência territorial e na atração de investimentos.

Um dos aspectos que pode interferir na constituição de novas ou renovadas instituições voltadas para a discussão do desenvolvimento é a consideração das redes sociopolíticas construídas nas localidades e o acúmulo de experiências políticas voltadas para a participação da sociedade civil nos processos de decisão. A inclusão da sociedade civil deve ser tida como elemento necessário para captar a natureza das mudanças pelas quais passam as instituições. $E$ isso requer, como afirmam Locke e Jacoby (1997, p.59), "que examinemos mais cuidadosamente as características qualitativas da sociedade civil (i.e, os atributos organizacionais de grupos diferentes e os padrões de interação entre eles) de modo a melhor entender como esses diferentes padrões moldam o comportamento de maneiras distintas".

Ao elaborar sobre essa temática, Locke (1995, p.12) afirma que os atores econômicos envolvidos em redes densas, mas relativamente igualitárias, terão mais facilidade de compartilhar informação, formar alianças, construir confiança ("trust") e resolver os conflitos através da negociação do que outras firmas e sindicatos situados em redes mais fragmentadas ou hierarquizadas. Como resultado, diferentes redes sócio-políticas vão moldar os entendimentos, recursos e, portanto, as escolhas estratégicas do atores econômicos locais em muitas formas diferentes.

No caso do ABC, de acordo com Daniel (2001) um dos aspectos que tornou viável a ampla articulação econômica, social e política que sustentou a Câmara Regional foi a percepção coletiva dos agentes envolvidos a respeito da possibilidade de implementação de uma estratégia de desenvolvimento econômico com recorte regional. Em outras palavras, os agentes envolvidos não tomam as tendências globais e a política macroeconômica como determinações irreversíveis sobre a economia do Grande $\mathrm{ABC}$; ao contrário, optam pelo caminho de, dadas as tendências gerais, construir localmente as condições adequadas para a implementação de um modelo de desenvolvimento com cidadania (KLINK, 2003). 
7) A questão da inovação política. Mesmo apresentando características diferentes, os exemplos de pesquisa apresentados revelam a constituição de novos mecanismos de organização institucional, em geral associados à problemática econômica e política regional. $\mathrm{O}$ caso da Câmara Regional do $\mathrm{ABC}$ baseia-se em um conjunto de conceitos teóricos que apontam para uma prática política bastante diferente da tradição brasileira, inspirada no conceito de região ou território, o que implica uma importante inovação na forma de fazer política, na ampliação do conceito de cidadania, na democratização de decisões políticas, na maior participação da sociedade civil, o que sugere uma nova relação entre o público e o privado, baseada na negociação e na responsabilidade social dos vários atores para com a região. (LEITE, 2003).

Segundo Daniel (2001), esse modelo de desenvolvimento regional incorporou o tema da inclusão social, evidenciando que, nesses termos, procura-se formular uma estratégia de ação calcada na idéia de democracia como objetivo a ser alcançado (através da igualdade social) e na perspectiva da valorização da cidadania, aliando a democracia como meio e com fim: como meio, na medida em que a participação ampla e plural - nos âmbitos do Estado e da sociedade - é condição para o estabelecimento de acordos regionais; como fim, no sentido de basear-se numa estratégia de desenvolvimento que incorpora o tema da inclusão social.

Recebido em 9 de abril de 2008 Aprovado em 17 de abril de 2008

\section{Referências}

ABREU, A.; GITAHY, L.; RAMALHO, J. \& RUAS, R. Produção Flexível e Relações Inter-firmas: A indústria de autopeças em três regiões do Brasil. In: ABREU, A. (org.), Produção flexível e novas institucionalidades na América Latina. Rio de Janeiro: UFRJ, 2000. ABREU, A.; BEYNON, H. \& RAMALHO, J. "A fábrica dos sonhos" da Volkswagen. In: RAMALHO, J. \& SANTANA, M. (orgs). Trabalho e desenvolvimento regional. Efeitos sociais da indústria automobilística no Rio de Janeiro. Rio de Janeiro: Mauad X, 2006. 
APPAY, B. Individuel et collectif: questions à la sociologie du travail, et des professions: l'autonomie contrôllée". Cahier du GEDISST, n. 6. Paris, 1993.

. Précarisation sociale et restructurations productives. In: APPAY, B. \& THÉBAUD-MONY, A. (orgs.). Précarisation sociale, travail et santé. Paris: Iresco, 1997.

ARBIX, G. Uma aposta no futuro. Os primeiros anos da câmara setorial da indústria automobilística. São Paulo: Scritta, 1996.

CASTEL, R. As transformações da questão social. In: CASTEL, R; WANDERLEY, L. \& Belfiore-Wanderley, M. (orgs). Desigualdade e a questão social. São Paulo: EDUC, 1997.

COCCO, G.; GALVÃO, A. \& SILVA, M. Desenvolvimento local e espaço público na Terceira Itália. In: COCCO, G.; URANI, A. \& GALVÃO, A. (orgs.). Empresários e empregos nos novos territórios produtivos: o caso da Terceira Itália. Rio de Janeiro: DP\&A, 1999.

COUTROT, T. L'entreprise néo-libérale, nouvelle utopie capitaliste? Paris: Éditions de la Découverte, 1998.

DANIEL, C. 2001. Uma experiência de desenvolvimento econômico local: a câmara regional do Grande ABC. In: GUIMARÃES, N. \& MARTIN, S. (orgs.). Competitividade e desenvolvimento. Atores e instituições locais. São Paulo: Senac.

KLINK, J. Secretaria de Relações Internacionais e Captação de Recursos da Prefeitura de Santo André: Novos Desafios através de uma Visão Estratégica. Global, Rio de Janeiro, n. 0, 2003.

LEITE, M. Trabalho e sociedade em transformação: mudanças produtivas e atores sociais. São Paulo: P. Abramo, 2003.

LINHARDT, D. Souffrance individuelle et action collective. In: DURAND, J. P. (org.). Le syndicalisme au futur. Paris: Syros, 1996.

LOCKE, R. Remaking the italian Economy. New York: Cornell, 1995. LOCKE, R. \& JACOBY, W. The Dilemmas of Diffusion: Social Embeddedness and the Problems of institutional Change in Eastern Germany. Politics and Society, v. 25, n. 1, 1997.

PIORE, M. \& SABEL, C. The second industrial divide: possibilities for Prosperity. New York: Basic Books, 1984. 
PIRES, E. O desenvolvimento territorial na integração: estratégias, instituições e políticas. São Paulo: DEPLAN/CEAPLA/IGCE/UNESP, 2004.

RAMALHO, J. Trabalho e sindicato: posições em debate na sociologia hoje. Dados, Rio de Janeiro, v. 42, n. 4, 2000.

. Novas conjunturas industriais e participação local em estratégias de desenvolvimento. Dados, Rio de Janeiro, v. 48, n. 3, 2005.

RAMALHO, J. \& SANTANA, M. (orgs). Trabalho e desenvolvimento regional. Efeitos sociais da indústria automobilística no Rio de Janeiro. Rio de Janeiro: Mauad X, 2006.

RODRIGUES, I. \& RAMALHO, J. Trabalho e sindicato em antigos e novos territórios produtivos. São Paulo: Annablume, 2007.

. Trabalhadores, indústria automotiva e região: por que comparar o ABC paulista com o Sul fluminense? In: RODRIGUES, I.J. \& RAMALHO, J.R. (orgs). Trabalho e sindicato em antigos e novos territórios produtivos. São Paulo: Annablume, 2007a. 
